\title{
Identifying Psychological and Socio-Economic Factors Affecting Motorcycle Helmet Use
}

\author{
Mahdi Quchaniyan Haqverdi \\ MSc. Faculty of Civil an Environmental Engineering, Tarbiat Modares University, Tehran, Iran \\ E-mail: mahdi.quchaniyan@yahoo.com \\ Seyedehsan Seyedabrishami \\ (Corresponding Author) \\ Assistant Professor, Faculty of Civil an Environmental Engineering, Tarbiat Modares University, \\ Tehran, Iran \\ E-mail: seyedabrishami@modares.ac.ir \\ John A Groeger \\ Professor of Psychology, Department of Psychology, University of Hull, Cottingham Road, Hull, HU6 \\ 7RX, United Kingdom. \\ E-mail: j.groeger@hull.ac.uk
}




\begin{abstract}
Sixty percent of motorcyclist fatalities in traffic accidents of Iran are due to head injuries, but helmet use is low, despite it being a legal requirement. This study used face-to-face interviews to investigate the factors associated with helmet use among motorcycle riders in Mashhad city, the second largest city in Iran. Principal Component Analysis (PCA) and Confirmatory Factor Analysis (CFA) were used for data reduction and identification of consistent features of the data. Ordered and multinomial logit analyses were used to quantify the influences on helmet use and non-use.

The data show that $47 \%$ of the sample used a helmet use, but a substantial proportion of these did not wear their helmet properly. In addition, $5 \%$ of motorcyclists believed that helmets reduced their safety. Norms, attitudes toward helmet use, risky traffic behavior and awareness of traffic rules were found to be the key determinants of helmet use, but perceptions of enforcement lacked influence. Duration of daily motorcycle trips, riding experience and type of job also affected helmet use. Results indicate that motorcyclist training, safety courses for offending motorcyclists and social programs to improve social norms and attitudes regarding helmet use are warranted, as are more effective law enforcement techniques, in order to increase proper use of helmets in Iranian motorcyclists. In addition, special safety courses should be considered for motorcyclists who have committed traffic violations.
\end{abstract}

Key words: Motorcyclist, Helmet use, enforcement, Factor analysis, Logit 


\section{Introduction}

Motorized two wheelers (MTW) provide little protection for their riders. Despite this lack of safety, they allow economical and convenient travel for a large portion of population in cities with street traffic congestion and inadequate public transit services (Musso et al., 2010; Tuan, 2012). Motorcyling constitutes a considerable share of urban travel in Iran (8\% in Mashhad), and is the main mode of transportation in some rural areas (Mashhad Traffic and Transportation Organization, 2012). The government of Iran is about to remove subsidies on gasoline and because of their comparatively lower gasoline consumption, the popularity of MTWs is expected to increase, especially in large cities.

In Iran a license is required for all types of MTWs. Thirty hours of training for theory and practice is necessary before the riding test. While there is no gender restriction on licensing, for cultural reasons, female motorcyclists are very rare.

Twenty-four percent of traffic accident fatalities in Iran are motorcyclists. As almost a third $(31 \%)$ of those who die are aged 18-24 years, this represents an enormous loss of potential years of life. Head injury is the main cause (61\%) of motorcylist fatality (Iranian Legal Medicine Organization, 2014).

Several studies have shown that motorcycle helmets reduce the severity of motorcyclists accidents and decrease the risk of death in crashes by as much as 40 percent (Keng, 2005; Savolainen and Mannering, 2007). Types of helmet worn and improper use of helmets also affect motorcyclists' protection considerably (Yu et al., 2011). Since 1970s, motivated by the proven or assumed benefits of motorcycle helmets, various projects involving comprehensive helmet legislation and regulations, have begun in different countries in order to promote the use of helmets (Kraus et al, 1995). Increased democracy, education level, per capita income, political stability, and more equitable income distribution within a country are associated with the enactment of road safety laws (Law et al., 2013). In Iran it has been illegal to ride a motorcycle without wearing a helmet since 2002. However, available observational statistics indicate a low rate of helmet use from zero in rural areas to 50 percent in the Central Business District (CBD) of Tehran (Zamani-Alavijeh et al., 2011; Mehri et al., 2011; World Health Organization, 2011).

Promoting the use of helmets by motorcyclists has always been difficult. Perceived limitations on visual and auditory capacities (Papadakaki et al., 2013; Hung et al., 2008; Ranney et al., 2010), subjective reports of helmet weight, and increased temperature when wearing helmets are among the reasons motorcyclists refuse to wear helmets (Li et al., 2008; 
Orsi et al., 2012). The inconvenience of carrying the helmet when the motocycle is parked is also seen as a deterrent to helmet use.

In societies where the importance of helmet use has not been publicised, modifying motorcyclists' routine behaviour constitutes a real challenge, and in countries such as Iran, social norms for the desirable use of helmets have not been established, and many people see helmet use as an unusual and unnecessary action. Because of this we would argue that the absence of relevant social norms and perceptions about helmet use are the main obstacles to helmet use (Ranney et al., 2010; Li et al., 2008; Skalkidou et al., 1999).

Furthermore, road users' psychological characteristics and mood also influence traffic behavior (Papadakaki et al., 2013; Stephens \& Groeger, 2011; Lund et al., 1991), and studies suggest that risky behaviors of different types are strongly inter-related. Thus, a single behavior such as helmet use should not be considered without considering other aspects of safe motorcycle riding behavior (Hung et al., 2008; Ranney et al., 2010) and the wider traffic system in which the behaviour of interest occurs (Groeger \& Rothengatter, 1998).

Thus far the effects of enforcement have been investigated less than other factors, and are mainly limited to roadside surveys before and after the start of the helmet law enforcement. Survey results from the US states of Texas, Arkansas and California have indicated an increase from approximately 50 percent helmet use before the law to 98 percent after the start of law enforcement (Kraus et al, 1995; Lund et al., 1991). Studying the impact of important factors such as level of police presence, size of penalties (e.g. cost of fines) and perception of enforcement strictness by motorcyclist, have been invetigated in previous studies, but findings are inconsistent (Zamani-Alavijeh et al., 2011; Hung et al., 2008; Li et al., 2008).

Impact of travel characteristics, such as trip length, road type, and urban and suburban environments have been investigated in several previous studies (Hung et al., 2008; Li et al., 2008; Skalkidou et al., 1999; Ambak et al., 2010; Yannis et al., 2012). However, these studies have not yielded consistent findings. Inconsistency in these results may be due to influence of road type on whether motorcyclists considered helmet use necessary, as well as variation of enforcement across different road types. Observational roadside studies have shown that motorcyclists are more likely to use helmets in winter, weekdays and early morning hours (Zamani-Alavijeh et al., 2011; Li et al., 2008; Skalkidou et al., 1999; Conrad et al., 1996; Gkritza, 2009), but have not revealed why these factors affect helmet use, or whether these factors are causal. 
Previous studies show that motorcyclists who are older, have higher levels of education and longer experience of motorcycling and those with a history of motorcycling injury, use helmets more than others (Papadakaki et al., 2013; Ranney et al., 2010; Ambak et al., 2010; Arosanyin, 2010; Hung et al., 2008; Kulanthayan et al., 2000). The consistency with which factors emerge in studies conducted in different countries is indicative of their importance.

This study aims to help decision makers to develop methods to increase helmet use by motorcyclists, by identifying which factors might influence future helmet use. We assumed that individual motorcyclists do not behave consistently with regard to helmet use in all circumstances, and for this reason we initially adopted discrete choice models in an attempt to characterise helmet use behaviour. Discrete choice models are used to modeling probabilities and using econometric tools to make probabilistic statements about the occurrence of individual choices (Greene, 2010). We used this approach to evaluate the influence of a broad range of factors on helmet use, including: beliefs associated with helmet use, the influence of indiviual attitudes and social norms on helmet use, as well as the effects of enforcement- real and implied, and perceived likelihood of detection or apprehension.

\section{Methods}

\subsection{Participants}

Of 222 potential respondents approached, all but 2 completed interviews. All respondents were male, as there are very few female motorcyclist in Iran. Respondents were aged at least 18 years, and the average age of sample was 31 years. $65 \%$ of respondents were married. The vast majority of participants were residents of Mashhad (86\%), and 32\% were employed as service workers. On average participants had 11 years of motorcycling experience.

\subsection{Procedure}

The data reported below were all collected in January 2012 from respondents interviewed at motorcycle repair shops, selected at random in zones of poor and middle income in Mashhad city, because upper income households almost use private cars. Mashhad is Iran's second largest city, with a population of 2.9 million (Mashhad Traffic and Transportation Organization, 2012). Interviews were performed for quantitative research and 
carried out between 15:00 and 20:00, the peak hours for repair shops. During January 2012, Weather Underground (http://www.wunderground.com) shows the weather at Mashhad Airport to have ranged in temperature from $-4 \mathrm{C}$ to $7 \mathrm{C}$ (average 1C), $0 \mathrm{~mm}$ average precipitation and wind between $0 \mathrm{~km} / \mathrm{h}$ and $34 \mathrm{k} / \mathrm{mh}$ (average $6 \mathrm{k} / \mathrm{mh}$ )

Previously, pilot interviews were carried out on 24 respondents at gas stations, parking lots and a motorcyle repair shop. Participant recruitment was far more successful in the latter type of location. This pilot study determined the location and final structure of the questionnaire-led interviews in the main study. The first author and three volunteer university students, who were informed in advance about the interview purpose and research objectives, performed the interviews.

\subsection{Interview design}

As described above, the final form of the interviews was determined following a pilot study. It was decided to concentrate on five areas, each drawing on previous literature, while also reflecting the social features of Iran.

Demographics: This section focused on socioeconomic characterictics of respondents, including age, marital status, household size, employment, place of residence, and income.

Motorcycling experience and risk exposure: This section questioned respondents on their ownership of motorcycles, years of riding experience, purposes for which motorcycle is used (e.g. recreation, travel to work/education, etc), use of highways, average trip duration (minutes) and trips frequency (number of days per week of motorcycle use).

Beliefs, attitudes and behaviour: This section consisted of 24 questions which asked about perceptions of enforcement, norms and attidudes towards helmet use, risky riding behaviour, see Table 1.

Accident experience: This section assessed respondents' accident experience. It used three questions to assess whether the respondent had (a) seen the death of another motorcyclist, (b) been injured seriously while motorcycling and (c) whether there had been any deaths among family and friends in motorcycle accidents.

Self reported helmet use: This final section sought to characterise the respondent' helmet use and attitudes towards helmet use. It was asked whether the rider had ever worn a helmet, and if so, the number of years over which a helmet was worn. [The latter, subtracted from the number of years of riding experience allowed the calculation of habitual helmet non-use]. Respondents were asked which statement about helmet ownership and use best characterised their behaviour: No helmet ownership, Own but do not carrry helmet, Carry but do not wear 
helmet, Wear helmet incorrectly, Wear helmet correctly. Where the latter three options were chosen, the rider was asked to estimate the number of times (between 1 and 10) which best reflected their use in each case.

\subsection{Data handling and Statistical analyses}

The main analyses reported here adopted a two phase approach: Principal Components Analysis (PCA) and Confirmatory Factor Analysis (CFA) were used to reduce dimensions of data and combine variables, and subseqently multinomial logit and ordered logit models are used to describe the behavior of motorcyclists and estimate the effect of each factor on helmet use. SPSS 20 and Nlogit 4 were used for the analysis.

Factor Analysis is a statistical method for analyzing available information in the data set. The output of this method is a classification of variables that are most relevant to each other and the extraction of factors representing the variables in each category (Washington et al., 2010).

Table 1 Beliefs, attitudes, and perceptions of enforcement related to helmet use

\begin{tabular}{|c|l|l|}
\hline No. & Question & Answer format \\
\hline 1 & Do your family and friends use helmets? & $\begin{array}{l}\text { none of them is motorcyclist, no one, some of } \\
\text { them, most of them }\end{array}$ \\
\hline 2 & How would you describe public views of safety helmet use? & unusual, usual, completely usual \\
\hline 3 & What is the reaction of your friends to helmet use? & mocking, indifferent, encouraging \\
\hline 4 & What is the reaction of your family to helmet use? & mocking, indifferent, encouraging \\
\hline 5 & Have you been exposed to the advertising related to helmet use? & never, one or two times, several times \\
\hline 6 & Do you know that helmet use is required by law? & not aware, aware \\
\hline 7 & $\begin{array}{l}\text { What is your perception of the presence of enforcement on the } \\
\text { routes you use? }\end{array}$ & never, sometimes happens, strictly imposed \\
\hline 8 & What is your perception of effectiveness of current enforcement? & ineffective, barely effective, completely effective \\
\hline 9 & How much is the fine price for not using helmet $(\$ 13)^{1} ?$ & correct, incorrect \\
\hline 10 & $\begin{array}{l}\text { How many times you might be fined in a year if you do not use } \\
\text { helmet at all? }\end{array}$ & number of times per year \\
\hline 11 & How much long is it helmet use became mandatory by law ? & year \\
\hline 12 & $\begin{array}{l}\text { Do you believe the current } \$ 13 \text { penalty for helmet non-use is } \\
\text { effective? }\end{array}$ & not effective, low effective, completely effective \\
\hline 13 & Should helmet use enforcement increase? & should not interfere, adequate, should increase \\
\hline 14 & How do you feel when police fine an offending motorcyclist? & that it is unfair, indifferent, that it is appropriate \\
\hline 15 & What is the motorcycle speed limit on expressways $(80 \mathrm{~km} / \mathrm{h}) ?$ & correct, incorrect \\
\hline 16 & How affordable, for you, is a standard quality helmet $(\$ 15) ?$ & $\begin{array}{l}\text { too expensive, affordable, the cost is not much, } \\
\text { cost is not important }\end{array}$ \\
\hline
\end{tabular}

\footnotetext{
${ }^{1}$ According to the World bank (2013), Iran's Gross National Income per capita was $\$ 5780$ per annum (Retrieved, January 2015). And thus the fine represents approximately $2.5 \%$ of GNI averaged monthly income, which would be the equivalent of a fine of $\$ 86$ (UK) or \$111 (US).
} 


\begin{tabular}{|c|l|l|}
\hline 17 & $\begin{array}{l}\text { How difficult is it for you to keep your helmet with you having } \\
\text { parked? }\end{array}$ & not difficult, quite difficult, difficult \\
\hline 18 & What is the effect of helmets on motorcycle safety? & $\begin{array}{l}\text { negative, not effective, low effective, completely } \\
\text { effective }\end{array}$ \\
\hline 19 & Does helmet wearing reduce vision and hearing? & not at all, a little, a lot \\
\hline 20 & How easy is helmet use during the summer? & not difficult, difficult, unbearable \\
\hline 21 & Do you agree that experienced riders should use helmets? & disagree, agree, completely agree \\
\hline 22 & $\begin{array}{l}\text { Do you agree that helmets should be used on short trips while } \\
\text { riding cautiously? }\end{array}$ & disagree, agree, completely agree \\
\hline 23 & $\begin{array}{l}\text { Do you ride on restricted carriageways in order to shorten your } \\
\text { journey? }\end{array}$ & never, sometimes, usually \\
\hline 24 & Do you talk on a cell phone while motorcycling? & never, sometimes, usually \\
\hline
\end{tabular}

The mathematical equation is as follows (Washington et al., 2010):

$\mathbf{x}=\mathbf{\Lambda} \mathbf{f}+\mathbf{e}$

Subject to:

$E[\mathbf{e}]=\mathbf{0}, E[\mathbf{f}]=\mathbf{0}, E[\mathbf{x}]=\mathbf{0} ;$

where, $\mathbf{x}$ is the vector of random variables, $\boldsymbol{\Lambda}$ is the coefficients matrix, $\mathbf{f}$ is the vector of factors and $\mathbf{e}$ is an error vector. If it can be determined in advance what variables should comprise each factor, confirmatory factor analysis (CFA) is preferred.

PCA is a linear statistical method to reduce dimension of data and interpretation of complex data. The output of this method is a categorization of variables based on their correlations with each other (Jolliffe, 2005). Varimax orthogonal rotation is also used to improve the interpretability of the results of principal component analysis. In this study, the components derived from PCA are used as a guide for CFA.

Since helmet use is considered as a choice on the part of participants in this study, a discrete choice modeling approach was used. Discrete choice models are based upon the assumption that decision makers (motorcyclist participants in this study) choose the alternative with maximum utility to them of particular choices. Whereby the greater the utility of an option, the more likely it is to be selected by a decision maker.

Equation (3) represents the utility function of alternative $i$ for individual $n$ (Washington et al., 2010):

$\mathrm{U}_{\mathrm{ni}}=\beta_{\mathrm{i}} \mathrm{x}_{\mathrm{ni}}+\varepsilon_{\mathrm{ni}}$;

where, $\mathrm{U}_{\mathrm{ni}}$ is the utility of alternative $i$ for individual $n$ and $\varepsilon_{\mathrm{ni}}$ is an unobserved part of the utility function or "disturbance term". The observed or definite part of the utility for individual $n$ is shown by $\beta_{\mathrm{i}} \mathrm{x}_{\mathrm{ni}}, \beta_{\mathrm{i}}$ is the coefficient vector for alternative $i$ and is estimated at different modeling stages.

The underlying assumption is that a decision maker will select an alternative that affords the greatest personal utility. This has led to the concept of random utility models in 
which the probability of choosing an alternative is equal to probability of its utility being more than the utility of other alternatives and is expressed as equation (4).

$P_{n i}=\operatorname{Pr}\left(U_{n i}>U_{n j}, \forall j \neq i\right)$;

where $\mathrm{P}_{\mathrm{ni}}$ is probability of choosing alternative $i$ for individual $n$ and $\mathrm{U}_{\mathrm{nj}}$ is the utility of each alternative for individual $n$.

In multinomial logit models, the distribution function for the error in the utility function is assumed as gumbel type 1 (Washington et al., 2010), and probability of choosing alternative $i$ for individual $n$ can be estimated by equation(5).

$\mathrm{P}_{\mathrm{ni}}=\frac{\exp \left(\beta_{\mathrm{i}} \mathrm{x}_{\mathrm{ni}}\right)}{\sum_{\forall \mathrm{I}} \exp \left(\beta_{\mathrm{I}} \mathrm{x}_{\mathrm{nI}}\right)}$

where $I$ is the set of alternatives (Washington et al., 2010).

For discrete data which are ordinal in nature, ordered discrete choice models are used. Ordered probabilistic models are drived by defining a hidden variable $z$. This hidden variable is typically identified by a linear function for each observation, so that:

$\mathrm{z}_{\mathrm{n}}=\beta \mathrm{x}_{\mathrm{n}}+\varepsilon_{\mathrm{n}}$

where, $x$ is the vector of independent variabls for observation $n, \beta$ is the vector of estimated parameters and $\varepsilon$ is the disturbance term. By this equation, ordered data $y$, estimated for each observation is defined as:

$\mathrm{y}=0 \quad$ if $\quad \mathrm{z} \leq \mu_{0}$;

$\mathrm{y}=1 \quad$ if $\quad \mu_{0}<z \leq \mu_{1}$;

$\mathrm{y}=2 \quad$ if $\quad \mu_{1}<z \leq \mu_{2}$;

$\mathrm{y}=\mathrm{I} \quad$ if $\quad \mu_{\mathrm{I}-1}<z$;

where, values of $\mu$ are estimable and set the thresholds for $y$, and $I$ is the maximum ordinal discrete value possible for $y$, and $\mathrm{z}$ is a hidden variable explained in equation (6) (Washington et al., 2010).

\section{Results}

The purpose of this study was to investigate the factors affecting helmet use. Because of the large number of variables investigated, factor analyses with PCA and CFA were performed for data reduction and identification of consistent features of the data. Ordered and multinomial logit analyses were used to quantify the influences of investigated factors and variables on helmet use. First we consider the data in descriptive terms. 


\subsection{Helmet usage and riding behavior}

Of 220 motorcyclists interviewed, 28 (12.7\%) reported not possessing a helmet. Motorcylists who owned a helmet stated that helmets were not carried for an average 3.25 out of ten trips, carried but not worn on 0.8 occasions, and helmets were used without fastening the chin strap on 1.33 out of ten trips. Thus, participants stated that on 3.35 out of ten trips helmets were used properly (Table 2). That is, of those questioned 47.6 percent used helmets, and only one third of cases wore their helmet properly (i.e. unfastened helmets are likely to leave the head unprotected immediately on impact, and hence the riders unprotected head is more likely to make contact with the group or other obstacles). In contrast to these figures, helmet ownership (87.4\%) is very high. Five percent considered that helmets are ineffective or have a negative effect on safety, while $23 \%$ considered helmets unbearable in summer heat and $33 \%$ percent stated that helmets decrease vision and hearing.

Table 2 Average probability of helmet use alternatives and standard deviations according to motorcyclists saying

\begin{tabular}{|c|c|c|c|c|c|}
\hline Alternatives & $\begin{array}{c}\text { Do not own a } \\
\text { helmet }\end{array}$ & $\begin{array}{c}\text { Owned but not } \\
\text { carried }\end{array}$ & $\begin{array}{c}\text { Carried but not } \\
\text { worn }\end{array}$ & $\begin{array}{c}\text { Worn without } \\
\text { fastened chin strap }\end{array}$ & Worn correctly \\
\hline Average & 0.127 & 0.325 & 0.080 & 0.133 & 0.335 \\
\hline SD & 0.33 & 0.397 & 0.193 & 0.289 & 0.410 \\
\hline
\end{tabular}

Almost half (44\%) of the sample had been seriously injured when motorcycling in their life, which reflects the serious chalenge of motorcycle safety in Mashhad.

In relation to risky traffic behaviors, $31 \%$ of motorcyclists stated they usually used illegal directions of travel and $23 \%$ usually talk on a cell phone while motorcycling. Only 36 percent of participants were aware of regulations for motorcycle speed limits on expressways, even though Mashhad has a network of expressways.

Questions were also asked regarding motorcylists understanding of traffic regulations relating to helmet use. Thirty five percent considered it unfair when police fine a motorcyclist at all, and $17 \%$ did not consider an increase in helmet use enforcement necessary. Ten percent of participants were not aware of the mandatory helmet use law . Of those aware of the legal requirement to wear helmets, $10 \%$ considered the current helmet use enforcement ineffective.

\subsection{Factor analysis}


Twenty-four questions were used to assess the attitudes and tendencies of motorcyclists toward safety helmet-usage, their perception of enforcement and social norms. PCA and then CFA were used on responses in order to identify robust factors. KMO measure of sampling adequacy was 0.727 , indicating that PCA is acceptable for this sample. The solution resulting from PCA with varimax rotation was 7 interpretable components which explained 52 percent of the total sample variance. Parameters and the proportion of variance explained by each component after varimax rotation are presented in Table 3.

Table 3 Main components of tendency to motorcycle helmet use

\begin{tabular}{|c|c|c|}
\hline Component No., Component name & Coefficient & \begin{tabular}{|c|} 
Percent of \\
variance explained
\end{tabular} \\
\hline \multicolumn{2}{|l|}{ 1. Tendency to use a helmet } & 11 \\
\hline Do you agree that helmets should be used on short trips while riding cautiously? & 0.74 & \\
\hline Do you agree that experienced riders should use helmets? & 0.74 & \\
\hline Does helmet wearing reduce vision and hearing? & -0.61 & \\
\hline How easy is helmet use during the summer? & -0.48 & \\
\hline How do you feel when police fine an offending motorcyclist? & 0.45 & \\
\hline Should helmet use enforcement increase? & 0.41 & \\
\hline \multicolumn{2}{|l|}{ 2. Tendency to engage in risky traffic behaviors } & 9.7 \\
\hline Do you talk on a cell phone while motorcycling? & 0.78 & \\
\hline Do you ride on restricted carriageways in order to shorten your journey? & 0.74 & \\
\hline \multicolumn{2}{|l|}{ 3. Perception of helmet use enforcement } & 9 \\
\hline Do you believe the current $\$ 13$ penalty for helmet non-use is effective? & 0.80 & \\
\hline What is your perception of effectiveness of current enforcement? & 0.77 & \\
\hline Do you know that helmet use is required by law? & 0.75 & \\
\hline How many times you might be fined in a year if you do not use helmet at all? & 0.49 & \\
\hline \multicolumn{2}{|l|}{ 4. Drawbacks of helmet use } & 6.7 \\
\hline How affordable, for you, is a standard quality helmet $(\$ 15) ?$ & 0.73 & \\
\hline How difficult is it for you to keep your helmet with you having parked? & 0.54 & \\
\hline How easy is helmet use during the summer? & 0.48 & \\
\hline Does helmet wearing reduce vision and hearing? & 0.40 & \\
\hline \multicolumn{2}{|l|}{ 5. Effects of current helmet use enforcement } & 6.1 \\
\hline Do you know that helmet use is required by law? & 0.36 & \\
\hline How much long is it helmet use became mandatory by law? & 0.52 & \\
\hline What is your perception of the presence of enforcement on the routes you use? & 0.61 & \\
\hline How many times you might be fined in a year if you do not use helmet at all? & 0.62 & \\
\hline \multicolumn{2}{|l|}{ 6. Perception of social norms } & 5.4 \\
\hline Have you been exposed to the advertising related to helmet use? & 0.68 & \\
\hline How would you describe public views of safety helmet use? & 0.59 & \\
\hline \multicolumn{2}{|l|}{ 7. Awareness of traffic rules } & 5.3 \\
\hline What is the motorcycle speed limit on expressways $(80 \mathrm{~km} / \mathrm{h}) ?$ & 0.74 & \\
\hline How much is the fine price for not using helmet? & 0.56 & \\
\hline
\end{tabular}


The results of PCA in this study are similar to the results of Hung et al. (2008) where components such as "tendency to use helmet" and "difficulties of helmet use" were identified in that research. Papadakaki et al. (2013) also identified component "discomfort", simillar to "tendency to use a helmet" in Table 3, which reflects individuals' beliefs and perceptions of helmet use

One of the disadvantages of PCA is that all variables influence all components, and pre-determined categorisations of the contributing variables cannot be taken account of during the analysis. For this reason, PCA results were used as a guide for CFA. Results of CFA are presented in Table 4.

Table 4 Factors created by CFA and their variables

\begin{tabular}{|c|c|}
\hline Factor & Coefficient \\
\hline \multicolumn{2}{|l|}{ Tendency to use a helmet } \\
\hline Does helmet wearing reduce vision and hearing? & -0.73 \\
\hline Do you agree that experienced riders should use helmets? & 0.73 \\
\hline How easy is helmet use during the summer? & -0.68 \\
\hline Do you agree that helmets should be used on short trips while riding cautiously? & 0.66 \\
\hline How do you feel when police fine an offending motorcyclist? & 0.52 \\
\hline Should helmet use enforcement increase? & 0.47 \\
\hline What is the effect of helmets on motorcycle safety? & 0.34 \\
\hline How difficult is it for you to keep your helmet with you having parked? & -0.32 \\
\hline How affordable, for you, is a standard quality helmet $(\$ 15) ?$ & 0.27 \\
\hline \multicolumn{2}{|l|}{ Perception of helmet use enforcement } \\
\hline Do you know that helmet use is required by law? & 0.94 \\
\hline What is your perception of effectiveness of current enforcement? & 0.76 \\
\hline Do you believe the current $\$ 13$ penalty for helmet non-use is effective? & 0.59 \\
\hline What is your perception of the presence of enforcement on the routes you use? & 0.61 \\
\hline How much long is it helmet use became mandatory by law? & 0.35 \\
\hline How many times you might be fined in a year if you do not use helmet at all? & 0.11 \\
\hline \multicolumn{2}{|l|}{ Perception of social norms } \\
\hline What is the reaction of your friends to helmet use? & 0.95 \\
\hline What is the reaction of your family to helmet use? & 0.54 \\
\hline Do your family and friends use helmets? & 0.34 \\
\hline How would you describe public views of safety helmet use? & 0.29 \\
\hline \multicolumn{2}{|l|}{ Tendency to engage in risky traffic behaviors } \\
\hline Do you talk on a cell phone while motorcycling? & 0.86 \\
\hline Do you ride on restricted carriageways in order to shorten your journey? & 0.86 \\
\hline \multicolumn{2}{|l|}{ Awareness of traffic rules } \\
\hline What is the motorcycle speed limit on expressways $(80 \mathrm{~km} / \mathrm{h}) ?$ & 0.73 \\
\hline How much is the fine price for not using helmet? & 0.73 \\
\hline
\end{tabular}


The factor "perception of social norms" is negativly correlated with "tendency to engagement in risky traffic behaviors" $(\rho=-0.36$, p-value $<0.01)$ and positively correlated with "tendency to use a helmet" $(\rho=0.44$, p-value $<0.01)$, but other correlations between factors are small and suggest that otherwise factors are independent.

Table 5 shows changes in the mean values of the six confirmatory factors between different types of helmet use. The factors "perception of social norms" and "tendency to use a helmet" gradually increase from the first alternative to fifth (p-value $<0.0001)$. A similar trend is also present for "perception of helmet use enforcement" but it is heavily weighted towards responses indicating that helmets are worn without fastening chin strap, rather than used correctly ( $p$-value $<0.0001)$. The factor "tendency to engage in risky traffic behaviors" is relatively constant in alternatives first to third types of usage (i.e. not using a helmet at all) but is lower among those who wear helmets, even if they do not do so properly (p-value < 0.0001). "Awareness of traffic rules" is lower for those who report "carrying a helmet but not wearing it" and only has significant positive value for those who report "Wearing the helmet but not fastening its chin strap".

Table 5 Mean values of confirmatory factors between different alternatives of helmet use

\begin{tabular}{|l|c|c|c|c|c|}
\hline Confirmatory factor & $\begin{array}{c}\text { Do not own a } \\
\text { helmet }\end{array}$ & $\begin{array}{c}\text { Owned but } \\
\text { not carried }\end{array}$ & $\begin{array}{c}\text { Carried but } \\
\text { not worn }\end{array}$ & $\begin{array}{c}\text { Worn without } \\
\text { fastened chin } \\
\text { strap }\end{array}$ & $\begin{array}{c}\text { Worn } \\
\text { correctly }\end{array}$ \\
\hline Tendency to use a helmet & -0.36 & -0.27 & -0.08 & -0.03 & 0.43 \\
\hline Perception of helmet use enforcement & -0.15 & -0.06 & -0.01 & 0.13 & 0.07 \\
\hline Perception of social norms & -0.54 & -0.29 & -0.13 & 0.21 & 0.43 \\
\hline $\begin{array}{l}\text { Tendency to engage in risky traffic } \\
\text { behaviors }\end{array}$ & 0.25 & 0.23 & 0.29 & -0.14 & -0.32 \\
\hline Awareness of traffic rules & -0.03 & 0.01 & -0.29 & 0.12 & 0.03 \\
\hline
\end{tabular}

\subsection{Logit modeling}

This study used multinomial and ordered logit to establish which variables influence helmet use. Models are estimated with the assumption that acceptable significance level is almost 0.9 for the independent variables. Tables 6 and 7 present the dependent variables investigated together with their parameters and level of confidence. Both models were well fitted and described helmet use acceptably with similar results.

In the ordered model, riding experience is identified as a reliable variable that improves helmet use. Longer daily trips also increase the probability of helmet use, but the p- 
value for this does not reach conventional levels of significance. In multinomial logit, longer daily trips decrease likelihood of possessing a helmet but not carrying it, which means that for those who take longer trips and own a helmet, the likelihood of carrying the helmet increases.

It is possible that longer periods without helmet use makes it hard to change this habit and thus reduces the probability of future helmet use. In both multinomial and ordered logit models, this effect was confirmed.

Results of multinomial logit model indicate that tendency to use a helmet has high impact on proper helmet use. Importantly, the effect of understanding the necessity, importance of using helmets and ease of use, is more reliable than the effect of enforcement on helmet use.

Table 6 Variables and parameters in ordered logit model of helmet use

\begin{tabular}{|l|c|c|c|}
\hline \multicolumn{2}{|c|}{ Variable } & coefficient & p-value \\
\hline Constant & - & 1.055 & 0.0000 \\
\hline Tendency to use a helmet & confirmatory factor & 0.246 & 0.0000 \\
\hline Perception of social norms & confirmatory factor & 0.271 & 0.0466 \\
\hline $\begin{array}{l}\text { Tendency to engage in risky traffic } \\
\text { behavior }\end{array}$ & confirmatory factor & -0.092 & 0.0810 \\
\hline Habit of non-use of helmet & year & -0.104 & 0.0000 \\
\hline Riding experience & year & 0.096 & 0.0000 \\
\hline Daily trips duration & minute & 0.002 & 0.0750 \\
\hline \multirow{2}{*}{ Being university student } & yes=1 & 0.899 & 0.0015 \\
\cline { 2 - 4 } marginal parameter 1 & no=0 & 1.265 & 0.0000 \\
\hline marginal parameter 2 & - & 1.528 & 0.0000 \\
\hline marginal parameter 3 & - & 1.988 & 0.0000 \\
\hline \multicolumn{2}{|c|}{$\rho_{c}^{2}$} & -285 \\
\hline & & \multicolumn{2}{c|}{0.194} \\
\hline
\end{tabular}

In the ordered logit model, "tendency to engage in risky traffic behaviors" has a negative impact on helmet use. This finding is similar to the results of Hung et al (2008). This would suggest that risk taking and non-compliance with helmet use regulations are related. In addition, in multinomial logit model, "tendency to engage in risky traffic behaviors" reduces the probability of carrying a helmet but not wearing it and wearing the helmet properly. That is, those who more commit traffic violations are more lax about whether, and how, to use helmets. 
In the multinomial logit model, marital status and household size variables have acceptable levels of confidence. Being married reduces the probability of owning a helmet but not carrying it. Larger household size reduces the likelihood of carrying a helmet but not wearing it. This effect is somewhat similar to the effect of marital status. As Table 7 shows, other demogaphic variables are also influential: where educational level is elementery school or lower, the likelihood of not owning a helmet and carring the helmet but not wearing it is increased. Occupational status also influenced helmet use: those who work on the land are less likely to own a helmet, whereas those with manufacturing jobs are more likely to own a helmet, but are not more likely to wear it correctly.

Table 7 Variables and parameters in multinomial logit model of helmet use

\begin{tabular}{|c|c|c|c|c|c|c|c|c|c|c|c|}
\hline \multicolumn{2}{|l|}{ Variable } & \multicolumn{2}{|c|}{$\begin{array}{l}\text { Do not own a } \\
\text { helmet }\end{array}$} & \multicolumn{2}{|c|}{$\begin{array}{l}\text { Owned but not } \\
\text { carried }\end{array}$} & \multicolumn{2}{|c|}{$\begin{array}{l}\text { Carried but not } \\
\text { worn }\end{array}$} & \multicolumn{2}{|c|}{$\begin{array}{l}\text { Worn without } \\
\text { fastened chin } \\
\text { strap } \\
\end{array}$} & \multicolumn{2}{|c|}{ Worn correctly } \\
\hline & & \multirow{2}{*}{$\begin{array}{c}\text { Co. } \\
-1.337\end{array}$} & \multirow{2}{*}{$\frac{\mathrm{p} \text {-value }}{0.0007}$} & \multirow{2}{*}{$\frac{\text { Co. }}{1.419}$} & \multirow{2}{*}{$\frac{\mathrm{p} \text {-value }}{0.0006}$} & \multirow{2}{*}{$\begin{array}{c}\text { Co. } \\
0.035\end{array}$} & \multirow{2}{*}{\begin{tabular}{|l|} 
p-value \\
0.9716
\end{tabular}} & \multirow{2}{*}{$\begin{array}{c}\text { Co. } \\
-0.362\end{array}$} & \multirow{2}{*}{\begin{tabular}{|l|}
$\mathrm{p}$-value \\
0.2639 \\
\end{tabular}} & \multirow[t]{2}{*}{ Co. } & \multirow[t]{2}{*}{ p-value } \\
\hline Constant & - & & & & & & & & & & \\
\hline Tendency to use a helmet & $\begin{array}{l}\text { confirmatory } \\
\text { factor }\end{array}$ & & & & & & & 0.583 & 0.0287 & 0.857 & 0.0002 \\
\hline Perception of social Norms & $\begin{array}{l}\text { confirmatory } \\
\text { factor }\end{array}$ & -0.929 & 0.0010 & -0.648 & 0.0024 & & & -0.582 & 0.0378 & & \\
\hline $\begin{array}{l}\text { Tendency to engage in } \\
\text { risky traffic behavior }\end{array}$ & $\begin{array}{c}\text { confirmatory } \\
\text { factor }\end{array}$ & & & & & 0.586 & 0.0413 & & & -0.516 & 0.0120 \\
\hline Awareness of traffic rules & $\begin{array}{c}\text { confirmatory } \\
\text { factor }\end{array}$ & & & & & -0.402 & 0.2215 & & & & \\
\hline Habit of not using helmet & Year & & & & & & & -0.0507 & 0.0687 & -0.0255 & 0.1409 \\
\hline Daily trips duration & Minute & & & -0.008 & 0.0513 & & & & & & \\
\hline \multirow{2}{*}{$\begin{array}{l}\text { No motorcyclists among } \\
\text { family and friends }\end{array}$} & yes $=1$ & & & \multirow{2}{*}{-1.301} & \multirow{2}{*}{0.0072} & & & & & & \\
\hline & $\mathrm{no}=0$ & & & & & & & & & & \\
\hline \multirow{2}{*}{$\begin{array}{l}\text { Education level be } \\
\text { elementary school and } \\
\text { lower }\end{array}$} & yes $=1$ & \multirow{2}{*}{0.964} & \multirow{2}{*}{0.0162} & & & \multirow{2}{*}{0.964} & \multirow{2}{*}{0.0162} & & & & \\
\hline & $\mathrm{no}=0$ & & & & & & & & & & \\
\hline \multirow{2}{*}{ Agriculture Job } & yes $=1$ & \multirow{2}{*}{1.588} & \multirow{2}{*}{0.0664} & & & & & & & & \\
\hline & no $=0$ & & & & & & & & & & \\
\hline \multirow{2}{*}{ Manufacturing job } & yes $=1$ & & & \multirow{2}{*}{1.238} & \multirow{2}{*}{0.0082} & \multirow{2}{*}{1.238} & 00082 & 1238 & 00082 & & \\
\hline & no $=0$ & & & & & & 0.0002 & 1.250 & 0.0002 & & \\
\hline Being university student & yes $=1$ & & & & & & & 2138 & 0.0213 & 2.504 & 0.0091 \\
\hline Being university student & no $=0$ & & & & & & & 2.158 & 0.0215 & 2.504 & 0.0091 \\
\hline Marital Status & Married=1 & & & -0.125 & 01335 & & & & & & \\
\hline Mrarital status & single $=0$ & & & -0.125 & 0.1555 & & & & & & \\
\hline Household size & Person & & & & & -0.557 & 0.0369 & & & & \\
\hline & Log Likelihoo & $l=-257$ & & & & & & $\rho^{2}=0$ & 269 & & \\
\hline & percent corr & $c t=54$ & & & & & & $\rho_{c}^{2}=0$ & 180 & & \\
\hline
\end{tabular}

\section{Discussion}

It should be emphasised at the outset that helmet use is a legal requirement in Iran, although helmet use rates are lower in Mashhad than some countries/state regions that do not have a helmet law (Kraus et al., 1995; Gkritza, 2009). Improper helmet use may affect 
whether the helmet remains attached to the head in a crash and thus reduce the helmet's effectiveness for preventing or reducing head injuries (Yu et al., 2011). Only two thirds of the self reported helmet use was proper usage. The extent of self reported for accident experience and of committing serious traffic violations are worrying.

The results indicate that probability of helmet use increases with riding experience, which confirms the results of Ranney et al (2010) in America and also Ambak et al (2010) in Malaysia. This suggests that experienced motorcyclists are less likely to do things that result in confrontation with the police, and over time these motorcyclists realize they are exposed to danger and so they tend to protect themselves more.

Logit modeling confirmed that the habit of not using a helmet reduces the probability of future helmet use. This implies a need for training programs for novice motorcyclists, which, by increasing personal awarenesses, might help to avoid adverse impact of adverse traffic habits and norms.

Norms have been identified as an influential factor on the different aspects of behaviors and behavioural intentions (Ajzen, 2011; Fishbein and Ajzen, 2010) and particularly in traffic safety behavior especially for young people (De Pelsmacker and Janssens, 2007; Cestac et al., 2011; Warner and Aberg, 2006). Similar influences are also apparent in this study with regard to helmet use. The impact of norms shows that part of the advertising of helmet use should be directed towards building positive public opinions and show the importance of helmet use for close relatives. Where there were no motorcyclists among family and friends, the probability of helmet use increased. That indicates that close relationships between motorcyclists influence decisions not to use helmets, and that family norms might also be a worthwhile focus of public education. I also seems likely, because the sampel is wholly male, that fathers of younger children may also be more responsible helmet users.

In this study, consistency of helmet use, or non-use, was high within individual riders, as previously shown by Lee et al (2008) and Hung et al (2008). However, overall helmet use is low, and future studies should consider using social programs that have been effective in changing the attitudes of motorcyclists to helmet use (e.g. Ratanavaraha and Jomnonkwao, 2013).

Perception of helmet use enforcement was signifisantly higher for improper use rather than proper use. This implies motorcyclists who do not use helmets properly are more sensitive to enforcement, although not sufficiently to provoke correct behaviour. 


\subsection{Limitations of the study}

This article only discusses the use of helmets by motorcycle riders, pillion passengers have not been considered, nor has the use of non-standard helmets. Investigation during warm half of the year was not possible because of time constraints, but given the reported seasonal influences on helmet-wearing, extending the data collection across all seasons is also warranted. In particular, the major limitation of the data reported here are based upon self-reported behaviour. Corroboration through roadside observation, perhaps even on entry to the interview locations, is obviously desirable. Another limitation is related to the lack of information on other factors that could affect helmet use, such as sensation seeking, sensitivity, socialability or unrealistic beliefs in own ability or vulnerability (see Groeger \& Grande, 1996).

\section{Summary and Conclusion}

Motorcycle safety helmets are an effective means of improving safety, at least in terms of reducing the seriousness of head injuries suffered. Helmet use is low in Mashhad city, but most of the motorcyclists who were not using helmets owned one. This indicates that most perceive the need to have a helmet, and thus more effort should be made to shift behaviour from merely owning to actual, and especially proper, use.

Previous studies identify a decisive role for enforcement on helmet use, but in this study no reliable effect was observed for perception of helmet use enforcement. Importantly, the effect of understanding the necessity and importance of using helmets and ease of use, is more reliable than the effect of perception of enforcement on helmet use. Given these results, it seems that enforcement has a desirable impact on individual behavior if it matches social norms and public education. This suggests that, in Iran, revision of current practices relating to enforcement is warranted. The extent of resources allocated to training programs and public education should also be increased, or the resources which are allocated must be used more effectively. Training programs may be especially appropriate for those without a college education, who work on the land or in manufacturing, and those who commit serious traffic violations, but, the results reported above show that interventions should be carefully tailored for each group if they are to be effective.

\section{References}

Ajzen, I., 2011. The theory of planned behavior. Handbook of Theories of Social Psychology: Collection: Volumes 1, 438-459. SAGE Publications Ltd, London. 
Ambak, K., Hashim, H., Yusoff, I., \& David, B. D., 2010. An evaluation on the compliance to safety helmet usage among motorcyclists in Batu Pahat, Johor. International Journal of Integrated Engineering, 2(2), 1-8.

Arosanyin, G. T., 2010. Earnings from commercial motorcycle operations in Ilorin, Nigeria: A Study on Determinants. Ghana Journal of Development Studies, 7(2), 77-95.

Cestac, J., Paran, F. \& Delhomme, P., 2011. Young drivers' sensation seeking, subjective norms, and perceived behavioral control and their roles in predicting speeding intention: How risk-taking motivations evolve with gender and driving experience. Safety science, 49(3), 424-432.

Conrad, P., Bradshaw, Y. S., Lamsudin, R., Kasniyah, N., \& Costello, C., 1996. Helmets, injuries and cultural definitions: motorcycle injury in urban Indonesia. Accident Analysis \& Prevention, 28(2), 193-200.

De Pelsmacker, P. \& Janssens, W., 2007. The effect of norms, attitudes and habits on speeding behavior: Scale development and model building and estimation. Accident Analysis \& Prevention, 39(1), 6-15.

Fishbein, M., \& Ajzen, I., 2010. Predicting and changing behavior: The reasoned action approach. Taylor \& Francis, New York.

Gkritza, K., 2009. Modeling motorcycle helmet use in Iowa: Evidence from six roadside observational surveys. Accident Analysis \& Prevention, 41(3), 479-484.

Greene, W.H., 2010. Econometric analysis. Prentice Hall, New Jersey.

Groeger, J.A. \& Grande, G.E., 1996. Self-preserving judgements of skill. British Journal of Psychology, 87, 61-79.

Groeger, J.A. \& Rothengatter, J.A., 1998. Traffic psychology and behaviour. Transportation Research Part F: Traffic Psychology and Behaviour, 1 (1), pp. 1-9.Hung, D. V.,

Stevenson, M. R., \& Ivers, R. Q., 2008. Barriers to, and factors associated, with observed motorcycle helmet use in Vietnam. Accident Analysis \& Prevention, 40 (4), 1627-1633.

Iranian legal medicine organization, 2014. http://www.lmo.ir/index.aspx?fkeyid=\&siteid=1\&pageid=2316\&newsview=15468.

Jolliffe, I., 2005. Principal component analysis. Springer, New York.

Keng, S. H., 2005. Helmet use and motorcycle fatalities in Taiwan. Accident Analysis \& Prevention, 37(2), 349-355.

Kraus, J. F., Peek, C., \& Williams, A., 1995. Compliance with the 1992 California motorcycle helmet use law. American Journal of Public Health, 85(1), 96-99.

Kulanthayan, S., Umar, R. R., Hariza, H. A., Nasir, M. M., \& Harwant, S., 2000. Compliance of proper safety helmet usage in motorcyclists. Medical Journal of Malaysia, 55(1), 4044.

Law, T. H., Noland, R. B., \& Evans, A. W., 2013. Factors associated with the enactment of safety belt and motorcycle helmet laws. Risk analysis 33 (7), 1367-1378.

Li, L. P., Li, G. L., Cai, Q. E., Zhang, A. L., \& Lo, S. K., 2008, Improper motorcycle helmet use in provincial areas of a developing country. Accident Analysis \& Prevention, 40(6), 1937-1942. 
Lund, A. K., Williams, A. F., \& Womack, K. N., 1991. Motorcycle helmet use inTexas. Public Health Reports, 106 (5), 576.

Mashhad Traffic and Transportation Organization, Office of Transportation Research, 2012. Eighth statistical report of Mashhad transportation, Mashhad, Iran.

Musso, A., Vuchic, V. R., Bruun, E. C., \& Corazza, M. V., 2010. A Research Agenda for Public Policy Toward Motorized Two-Wheelers in Urban Transport. Transportation Research Board 89th Annual Meeting. No. 10-0960.

Orsi, C., Stendardo, A., Marinoni, A., Gilchrist, M. D., Otte, D., Chliaoutakis, J. \& Morandi, A., 2012. Motorcycle riders' perception of helmet use: Complaints and dissatisfaction. Accident Analysis \& Prevention, 44(1), 111-117.

Papadakaki, M., Tzamalouka, G., Orsi, C., Kritikos, A., Morandi, A., Gnardellis, C. \& Chliaoutakis, J., 2013. Barriers and facilitators of helmet use in a Greek sample of motorcycle riders: Which evidence. Transportation Research part F: Traffic Psychology and Behaviour, 18, 189-198.

Ranney, M. L., Mello, M. J., Baird, J. B., Chai, P. R. \& Clark, M. A., 2010. Correlates of motorcycle helmet use among recent graduates of a motorcycle training course. Accident Analysis \& Prevention, 42 (6),2057-2062.

Ratanavaraha, V.\& Jomnonkwao, S., 2013. Community participation and behavioral changes of helmet use in Thailand. Transport policy, 25, 111-118.

Savolainen, P. \& Mannering, F., 2007. Probabilistic models of motorcyclists' injury severities in single-and multi-vehicle crashes. Accident Analysis \& Prevention, 39(5), 955-963.

Skalkidou, A., Petridou, E., Papadopoulos, F. C., Dessypris, N. \& Trichopoulos, D., 1999. Factors affecting motorcycle helmet use in the population of Greater Athens, Greece. Injury Prevention, 5(4), 264-267.

Stephens, A.N. \& Groeger, J.A., 2011. Anger-congruent behaviour transfers across driving situations. Cognition and Emotion, 25 (8), pp. 1423-1438

Tuan, V. A., 2012. Long-Term Motorcycle Traffic Management: Comparative Analysis of Motorcycle and Car Ownership Trends, Modal Split Changes, and Cross-Mode Performances in Asia. Transportation Research Board 91st Annual Meeting. No. 12-3187.

Warner, H. W. \& Aberg, L., 2006. Drivers' decision to speed: A study inspired by the theory of planned behavior. Transportation Research Part F: Traffic Psychology and Behaviour, 9(6), 427-433.

Washington, S. P., Karlaftis, M. G. \& Mannering, F. L., 2010. Statistical and econometric methods for transportation data analysis. Chapman and Hall/CRC, Boca Raton, FL.

World health statistics report: national legislation for motorcycle helmet. World health organization, New York, 2011. http://apps.who.int/gho/data/node.main.A1008.

Yannis, G., Laiou, A., Vardaki, S., Papadimitriou, E., Dragomanovits, A. \& Kanellaidis, G., 2012. A statistical analysis of motorcycle helmet wearing in Greece. Advances in Transportation Studies, 27.

Yu, W. Y., Chen, C. Y., Chiu, W. T. \& Lin, M. R., 2011. Effectiveness of different types of motorcycle helmets and effects of their improper use on head injuries. International journal of epidemiology, 40 (3), 794-803. 
Zamani-Alavijeh, F., Bazargan, M., Shafiei, A., \& Bazargan-Hejazi, S., 2011. The frequency and predictors of helmet use among Iranian motorcyclists: A quantitative and qualitative study. Accident Analysis \& Prevention, 43(4), 1562-1569. 